\title{
A INVESTIGAÇÃO HISTÓRICA NAS AULAS DE HISTÓRIA DA EDUCAÇÃO BÁSICA ${ }^{1}$
}

\section{HISTORICAL INVESTIGATION IN HISTORY CLASSES OF BASIC EDUCATION}

\author{
Astrogildo Fernandes da SILVA JÚNIOR* \\ Franciele Amaral Rodrigues SANTOS**
}

\begin{abstract}
RESUMO: Este texto apresenta resultados parciais de um projeto de pesquisa de iniciação científica que teve como objetivo geral analisar o potencial das diferentes fontes e linguagens da cultura contemporânea (filmes, canções, quadrinhos, obras de ficção, poesias, Internet, documentos, história oral, dentre outros) no processo de ensino e aprendizagem em história, particularmente, o papel destes na formação cidadã de jovens estudantes. De forma específica, são apresentadas algumas reflexões sobre uma das intervenções didáticas realizadas em turmas do nono ano do ensino fundamental, visando relacionar aspectos da história local com a história nacional. Para o desenvolvimento dessas atividades, optamos por utilizar jornais locais de diferentes épocas como fonte. Concluiu-se que experiências como essa possibilita a constituição do saber histórico dos estudantes.
\end{abstract}

PALAVRAS-CHAVE: Ensino de História. Diferentes fontes e linguagens. História Local.

\section{Introdução}

É importante que o profissional do ensino de história apresente aos alunos a função do aprendizado histórico na vida prática de cada um. Esse aprendizado histórico é um processo

1 Este artigo apresenta resultados de uma pesquisa apoiada pela FAPEMIG/CAPES/CNPq Editais: MCTI/CNPq/MEC/CAPES n. 18/2012 e 13/2012 - Pesquisa na Educação Básica Acordo CAPES e FAPEMIG; CNPq Universal/2016. Outras etapas do projeto já foram apresentadas em eventos científicos e publicadas em capítulo de livros e anais de evento. Porém, a etapa apresentada nesse artigo é inétida.

* Doutor em Educação (PPGED/UFU), professor da Faculdade de Educação da Universidade Federal de Uberlândia (FACED/UFU). ORCID : https://orcid.org/0000-0001-8983-4471, E-mail : silvajunior_af@yahoo.com.br

** Mestre em Educação (PPGED/UFU), professora de História da rede estadual de Minas Gerais. E-mail: ars.francielle@gmail.com 
que permite ao estudante refletir sobre a experiência temporal que o conhecimento histórico pressupõe, atribuindo sentido e orientação à vida prática e compreensão da identidade histórica e cultural dos indivíduos. A partir dessa compreensão, o estudo do passado traz algumas respostas para as inquietações vividas no presente. Portanto, faz-se necessário que os alunos entendam que o passado não está em um plano isolado, mas sim enraizado em nossas vidas hoje, pois tudo o que foi e é vivenciado faz parte das mudanças que gradualmente foram acontecendo no mundo.

Nesse sentido, um dos desafios do professor de história consiste em atribuir os elementos necessários para que os estudantes façam relação entre os conteúdos históricos com sua vida prática. É necessário um compromisso por parte do professor, em relação à responsabilidade de ensinar a melhor história possível.

Assim, atendendo ao comprometimento com os conteúdos e com a construção do saber histórico dos estudantes, desenvolvemos um projeto de pesquisa, ao longo de três anos, que teve como objetivo geral analisar o potencial das diferentes fontes e das diferentes linguagens da cultura contemporânea (filmes, canções, quadrinhos, obras de ficção, poesias,

Internet, documentos, história oral, jornais dentre outros) no processo de ensino e aprendizagem em história, particularmente o papel na formação cidadã de jovens estudantes. Neste texto, limitamo-nos em apresentar e refletir sobre uma intervenção didática realizada durante o projeto, com as turmas do nono ano do ensino fundamental, que visou relacionar aspectos da história local com a história nacional.

Didaticamente, o presente texto está organizado em três partes. Na primeira, apresentamos os pressupostos teóricos relacionados à história local e regional. Na segunda, a metodologia adotada. Na terceira, apresentação dos resultados de uma atividade didática desenvolvida com os estudantes do nono ano do ensino fundamental. Por fim, tecemos algumas considerações.

\section{Pressupostos teóricos}

De acordo com Bittencourt (2004), a história local e regional tem sido objeto de constantes debates entre historiadores e apresenta-se como desafio do ponto de vista teórico. A pesquisa de história local e regional cresceu bastante a partir dos anos de 1970 em razão do esgotamento das macro abordagens que enfatizavam as análises mais gerais e não se detinham nos estudos mais particulares que melhor indicavam as diferenças da história recente do País, tais como o incessante processo migratório, as disparidades socioeconômicas, a concentração 
de renda, o esvaziamento do meio rural, o crescimento urbano, entre outras realidades que modificavam profundamente a organização espacial brasileira.

A história local e regional passou a ser valorizada em virtude da possibilidade de fornecimento de explicações na configuração, transformação e representação social do espaço nacional, uma vez que a historiografia nacional ressalta as semelhanças, enquanto a regional trata das diferenças e da multiplicidade. Proporciona, na dimensão do singular, um aprofundamento do conhecimento sobre a história nacional, ao estabelecer relações entre as situações históricas diversas que constituem a nação.

Ao trabalhar com a história regional e local temos de ter o cuidado de não as inserir apenas em alguns momentos considerados significativos na história nacional. Chamamos a atenção pela raridade de materiais didáticos, o que em princípio pode apresentar dificuldade, pode se transformar em possibilidades, pois o professor, juntamente com os alunos, pode construir o material de estudo. Um dos caminhos é o trabalho com os documentos históricos escritos e visuais que podem evidenciar os diferentes sujeitos históricos e perceber os projetos em conflito nos diferentes períodos históricos.

Nesse sentido, pode-se transformar em um procedimento que "constrói" a história da região e, ao mesmo tempo, estimula diferentes habilidades nos estudantes como ler mapas e localizar os espaços estudados. Possibilita aos alunos se expressarem em diferentes linguagens como escrita, oral e visual. Permite a comparação da experiência histórica em diferentes épocas e diferentes espaços, além de possibilitar a relação entre elas. São atividades que incentivam a expressão oral e artística, bem como o desenvolvimento de múltiplas habilidades cognitivas, estimulando a observação, a comparação, a formulação de hipóteses, interpretação, argumentação, a análise, a síntese, a investigação, a criatividade, a autonomia no processo de aprendizagem, incentivando a pesquisa.

O trabalho com a história local e regional pode possibilitar que o aluno identifique as relações sociais no seu próprio grupo de convívio, na localidade, na região e no país, e outras manifestações estabelecidas em outros tempos e espaços. Dessa forma, a história local tem sido indicada como necessária para o ensino por levar a compreensão do entorno do aluno, identificando o passado sempre presente nos vários espaços de convivência como escola, casa, comunidade, trabalho e lazer, e igualmente por situar os problemas significativos da história do presente.

Um dos cuidados que devemos ter em relação à história regional é que esta não seja entendida como a história nacional. É importante estarmos atentos para não trabalhar a 
história local na perspectiva simplesmente de reproduzir a história do poder local e das classes dominantes. É possível identificar o enfoque e a abordagem de uma história local que crie vínculos com a memória familiar, do trabalho, da migração, das festas. Sendo assim contribui para a configuração identitária dos alunos.

De acordo com Bittencourt (2004), um cuidado que se deve ter com o estudo da história local é a identificação do conceito de espaço. Refletir sobre esse conceito é imprescindível para os estudos da história da região ou da história local, além de ser possibilidade de estudo interdisciplinar com a Geografia.

Nesse sentido, um dos conceitos fundamentais trabalhados é o de "lugar". Segundo o geógrafo Santos (1985), cada lugar tem suas especificidades e precisa ser entendido por meio da série de elementos que o compõe e de suas funções. Só pode ser compreendido dialeticamente levando-se em conta as relações de produção nele estabelecidas e sendo concebido como uma produção histórica. A história do lugar como objeto de estudo ganha, necessariamente, contornos temporais e espaciais. Não se trata, portanto, ao se propor conteúdos escolares da história local, de entendê-los apenas na história do presente ou de determinado passado, mas de procurar identificar a dinâmica do lugar, as transformações do espaço, e articular esse processo às relações externas, a outros "lugares".

Continuamos o texto apresentando a perspectiva metodológica utilizada no projeto e focando, especialmente, a sequência didática trabalhada com os estudantes do nono ano do ensino fundamental de uma escola pública da cidade de Ituiutaba-MG.

\section{Metodologia}

A pesquisa partiu de estudos do campo da didática da história, por acreditarmos que um dos lugares da pesquisa de campo didático-histórica é o cotidiano das aulas de História. A respeito dessa vertente, Cardoso (2008), afirma que a pesquisa didático-histórica não é o discurso de um antropólogo sobre um contexto familiar que ele precisa estranhar ou a crítica de um pedagogo à forma de organização das aulas do ponto de vista das ciências da educação. Ela é um discurso de um profissional da cultura histórica sobre essa mesma cultura, que tem um grande impacto, pois limita seu diálogo com outras disciplinas em função da coerência entre elas e a cultura histórica. Uma pesquisa de campo didático-histórica jamais ignora ou mesmo relega a segundo plano os conteúdos tratados numa aula. O que ocorre na sala de aula é apenas parte de um todo mais amplo, que engloba as elaborações da História sem forma 
científica. É só parte da cultura histórica, chamada de história escolar, que mantém relações indissociáveis com outras expressões dessa cultura.

Nesse sentido, consideramos que a sala de aula não se limita a lugar de reprodução, mas também de produção de conhecimentos. Sendo assim, ao longo do desenvolvimento do projeto propomos escutar professores e alunos, para juntos dos colaboradores da pesquisa, planejar aulas que incorporem as especificidades das diferentes fontes e linguagens, e as possíveis apropriações pelo ensino de história.

A investigação recorreu a elementos da pesquisa etnográfica em educação. André (1995), afirma que por meio de técnicas etnográficas de observação participante e de entrevistas intensivas, é possível documentar o não-documentado, ou seja, desvelar os encontros e desencontros que permeiam o cotidiano escolar.

Para Vianna (2007), a observação é uma das mais importantes fontes de informações em pesquisas qualitativas em educação. Para o autor, sem acurada observação não há ciência. Dessa forma, procuramos registrar as anotações realizadas nas visitas à escola e, em particular, das aulas de História, de forma detalhada com o intuito de reunir os dados brutos das observações. Não basta ao observador simplesmente olhar, mas é fundamental saber ver, identificar e descrever os diversos tipos de interações e processos humanos. Para isso, no trabalho de campo são sempre importantes a concentração, a paciência, o espírito alerta, a sensibilidade e a energia física para concretizar a tarefa.

Neste texto, nos limitamos em apresentar reflexões sobre a produção e desenvolvimento de uma sequência didática intitulada: "Onde estava minha cidade na História do Brasil?" Essa proposta foi desenvolvida no segundo semestre de 2015 em uma escola pública localizada na cidade de Ituiutaba-MG. Os sujeitos participantes deste trabalho foram três turmas do $9^{\circ}$ ano do período vespertino, juntamente ao professor de história da escola, que foi colaborador e bolsista durante os três anos de vigência do nosso projeto.

A sequência didática foi elaborada com o intuito de estimular a criatividade dos estudantes e atribuir ressignificação aos conteúdos estudados dentro de "um conjunto de atividades ordenadas, estruturadas e articuladas para a realização de determinados objetivos educacionais, que têm um princípio e um fim conhecido tanto pelos professores quanto pelos alunos" (ZABALA, 1998, p. 18) a partir do uso de linguagens, que permite aos alunos construir conceitos de forma dinâmica, sendo eles os protagonistas na construção do seu próprio saber histórico. 
O objetivo maior dessa sequência é a abordagem histórica voltada para a história local que intenciona levar os alunos a reconhecer que são parte integrante e de grande importância para a construção social do lugar, além de valorizar a história de sua cidade, compreendendo que a história do Brasil é constituída por cada canto existente no mapa nacional e que a história não se resume apenas aos acontecimentos dos grandes centros. A proposta do tema teve como intuito levar os alunos a pesquisarem os diferentes momentos da história do Brasil pré-estabelecidos relacionando-os à história de Ituiutaba-MG.

Para Raphael Samuel (1990, p. 220),

\begin{abstract}
A História local requer um tipo de conhecimento diferente daquele focalizado no alto nível de desenvolvimento nacional e dá ao pesquisador uma ideia muito mais imediata do passado. Ele a encontra dobrando a esquina e descendo a rua. Ele pode ouvir os ecos no mercado, ler o seu grafite nas paredes, seguir suas pegadas nos campos. [...] As pessoas estão continuamente colocando para si mesmas questões relacionadas ao local onde moram e sobre como viveram seus antepassados.
\end{abstract}

A partir dos ensinamentos do autor, consideramos que a valorização do estudo da história local na sala de aula faz com que a narrativa deixe de ser fundamentada em temas distantes e passe a ter uma amplitude da micro para a macro-história. Isso aproxima o aluno do conteúdo e da função que a história tem para a vida prática.

Os conteúdos programáticos abordados foram os períodos da história do Brasil, que faziam parte do currículo escolar: "Era Vargas (1930-1945)", "Democracia Populista (19451964)", “Ditadura Militar no Brasil (1964-1985)" e "Brasil Contemporâneo (1985-2008)". Com o intuito de organizar a sequência didática, foi dado um tema para cada turma do $9^{\circ}$ ano (A, B e C), sendo eles respectivamente "Política", "Economia" e "Cultura e Sociedade". Dessa forma, foi possível conciliar os conteúdos programáticos com os conceitos históricos, questão defendida por Karnal (2008).

Cada sala deveria pesquisar seu tema e relatar em forma de narrativa, de acordo com os períodos do conteúdo programático, relacionando com a história de Ituiutaba-MG. A turma do $9^{\circ}$ ano A ficou a cargo de buscar informações sobre o contexto político do município nos períodos de 1930 a 2008. Por sua vez, o $9^{\circ}$ ano B ficou incumbido de pesquisar sobre como era a economia municipal durante os períodos dados, e o $9^{\circ}$ ano $\mathrm{C}$ teve a importante tarefa de reunir registros e pesquisar sobre os aspectos culturais e o modo de vida da sociedade ituiutabana durante os anos 1930 a 2008. 
Para romper com a rotina da sala de aula, propusemos aos alunos um trabalho investigativo a partir da análise de jornais locais de diferentes épocas como fonte histórica para a realização da proposta da sequência didática e livros de apoio com a história de Ituiutaba-MG, encontrados na biblioteca municipal da cidade.

O jornal, assim como outras fontes, faz parte da inovação que se expandiu a partir do século XX em função das transformações teóricas no campo do conhecimento histórico com a intervenção da Escola dos Annales. A priori tínhamos uma história voltada para o econômico, o religioso e político, cujas fontes de pesquisas eram somente os documentos ditos oficiais. A partir do século XX temos grande ampliação do campo de atuação do historiador, pois, a partir do surgimento de novas temáticas e devido à alteração da concepção de documento histórico, passou-se a privilegiar outras fontes, dentre as quais se destacam os jornais. Desde então, pessoas comuns com suas diferentes experiências e modos de vida passaram a ser consideradas como sujeitos históricos fazendo parte da história das minorias que não estão nos documentos oficiais, ou nos livros didáticos, mas na memória e na história de sua própria região.

Os jornais pesquisados pelos estudantes foram alguns periódicos dos jornais locais de Ituiutaba-MG, "Diário Regional” década de 1980, 1990 e 2000; "Folha de Ituiutaba" década de 1960; "Cidade de Ituiutaba" década de 1970.

A primeira etapa do desenvolvimento da sequência didática foi problematizar com os alunos sobre a história de sua cidade e a própria comunidade. O que estava acontecendo em Ituiutaba durante o governo de Getúlio Vargas? Como era o cenário econômico? Que tipo de política era possível identificar nesse período? Como as pessoas viviam em sociedade, o que faziam para se divertir? De que forma estavam conectadas ao mundo cultural? Essas questões sobre política, economia e sociedade e cultura foram levantadas para todos os períodos propostos entre 1930 a 2008.

Consideramos que a sala de aula, enquanto espaço de produção de conhecimento histórico, permite o diálogo entre professores e alunos de forma a discutir e polemizar conteúdos; é o espaço no qual o aluno pode/deve emitir opiniões sobre o que está sendo estudado.

Na continuação da sequência didática, contextualizamos os períodos com os alunos em sala de aula. Para isso, contamos com o suporte do livro didático. Essa foi nossa segunda etapa: um estudo dirigido com o livro didático sobre os períodos da história do Brasil e a cada período estudado era feita a pesquisa supracitada sobre Ituiutaba-MG. No livro didático não 
encontramos conteúdo sobre história regional e local, portanto buscamos estudar o período proposto através de fontes encontradas na biblioteca municipal da cidade, dentre elas um livro que continha informações a respeito da história de Ituiutaba-MG, "Arcaica" de caráter memorialista da cidade. Elas trazem elementos que, analisados com cuidado, possibilitam traçar o perfil socioeconômico e cultural dos primórdios da cidade.

Inicialmente, os jornais que forneciam informações de interesse da pesquisa foram digitalizados, pois o arquivo onde se encontravam não tinha espaço suficiente para que os alunos o manuseassem in loco. As fontes digitalizadas foram trabalhadas nos horários das aulas de História no Laboratório de Informática da escola.

Como atividade extraclasse, os alunos se reuniam na biblioteca municipal da cidade para analisar os jornais e buscar complementos em livros direcionados à história da cidade. Essas reuniões foram supervisionadas por monitores colaboradores do projeto em questão.

Na finalização da sequência didática, foi organizado um evento na escola, no qual os estudantes, apresentaram suas reflexões. A atividade foi realizada no auditório e os estudantes produziram slides para a socialização dos resultados de suas pesquisas.

\section{Resultados}

O uso dos jornais como linguagem permitiu aos alunos exploração mais ampla do contexto político, econômico e cultural da cidade de Ituiutaba em interface com a história do Brasil. Ao analisar os periódicos foram encontradas respostas aos questionamentos iniciais dos estudantes e também ofertas de novos questionamentos, principalmente ao que se relaciona às questões locais que o jornal da cidade apresentava.

Percebemos que a proximidade dos alunos com as fontes históricas permitia não só a busca pelo conhecimento específico, mas também a transitar por outros caminhos que despertavam curiosidade e interesse sobre a história do município. Por exemplo, ao pesquisar sobre o comércio na tentativa que analisar o cenário econômico alguns alunos encontraram uma nota onde dizia que "para frequentar o cinema da cidade era necessário vestimenta adequada, para homens terno e para mulheres vestido longo social". (Jornal Folha de Ituiutaba, 03/04/1958). A partir desse recorte eles entenderam que isso fazia parte do modo de vida da sociedade naquela época, logo passaram o arquivo do jornal para os alunos que falariam sobre cultura e sociedade na década de 1950. 
A partir de informações do próprio jornal local desde a década de 1930 até os anos 1980, os alunos perceberam que a base econômica da cidade era quase que exclusivamente rural. A cidade já foi conhecida como a capital do arroz, devido à grande produção e exportação do produto.

As questões políticas também foram bem observadas, alguns alunos relacionaram vários políticos atuais da cidade que tem parentesco com os de décadas atrás. Essa etapa da sequência foi a mais interessante, pois materializa o que chamamos de função da história para vida prática, ou seja, compreender o nosso entorno e perceber que somos cercados por heranças do passado que interferem diretamente em nosso dia a dia no meio em que vivemos.

Através dessa experiência é possível dizer que o uso do jornal melhora a qualidade do ensino e das aulas de história, tornando o processo de ensino e aprendizagem mais dinâmico e interativo. Em nota de campo podemos fazer a leitura de parte da interação dos alunos com essa atividade.

Encontro 11/11/2015 - Quatro alunos do $9^{\circ}$ ano $\mathrm{C}$ ficaram responsáveis por pesquisar sobre os aspectos da sociedade e cultura em Ituiutaba-MG durante o período 1989 a 1990. Ao analisar alguns jornais do "Diário do Pontal" da década de 1990, encontraram informações sobre a programação de TV na cidade e a reação deles foi curiosa já que não se falava em celular ou tecnologias afins e que o entretenimento da criançada era desenho animado nos canais de TV aberta. A partir dessa informação eles fizeram um levantamento do panorama de programas de entretenimento na televisão brasileira nesse período: os desenhos que mais fizeram sucesso naquele momento foram Thundercats, caverna do Dragão, Smurfs, He-Man, Cavaleiros do Zodíaco, Pokémon, Tartarugas Ninja, Os Simpsons, entre outros. Outros programas que também chamavam atenção eram: Os Trapalhões, Carga Pesada, Show da Xuxa, TV Colosso, Domingão do Fustão, Casseta e Planeta, Rá-Tim-Bum e Catelo Rá-Tim-Bum. Alguns desses programas infantis marcaram os adultos de hoje. Algumas novelas levaram muitos brasileiros para o sofá e muitas vezes influenciavam na sua maneira de vestir, cortes de cabelos etc. Exemplos dessas novelas são: A próxima vítima, Mulheres de areia, Rei do gado, Rainha da sucata, entre outras. Ao associar esse período com a história de Ituiutaba-MG concluiu-se que alguns desses programas não eram transmitidos pelos canais disponíveis aqui como, por exemplo, Rá-Tim-Bum e Castelo Rá-Tim-Bum. Os alunos compreenderam que programas que influenciaram crianças dos grandes centros nem sempre fizeram o mesmo com crianças do interior.

A partir dessas considerações foi possível trabalhar com os estudantes os conceitos de mudanças e permanências relacionadas aos aspectos culturais. Os alunos refletiram sobre 
como a Internet marca a vida cotidiana no contexto atual, mas ressaltaram também que permanecem aspectos culturais como as novelas que também ditam modos de vestir e de viver.

A terceira etapa da sequência consistiu em sistematizar as informações selecionadas pelos alunos na pesquisa feita em jornais e livros de apoio. Essa sistematização foi feita em forma de narrativa. Os alunos produziram relatório que contextualizava o município de Ituiutaba-MG nos períodos estudados da história do Brasil. Nessa parte escrita do trabalho, os estudantes colocaram a metodologia usada para desenvolver a pesquisa, os resultados encontrados e nas considerações finais eles colocaram como foi a experiência com a abordagem das aulas. Em um dos trabalhos encontramos a seguinte consideração:

[...] o trabalho feito com os jornais foi muito legal. Tivemos a oportunidade de conhecer a história da cidade de uma forma diferente e descobrimos que teve uma época que se anunciava tudo no jornal, até quando se perdia e encontrava algo. ( $9^{\circ}$ A Grupo I, 2015).

[...] ver os jornais foi muito bom. Rimos de muitas notícias, é engraçado ver a forma como o povo se divertia antigamente e o mais triste é que naquela época não tinha celular. Nos jornais encontramos anúncios interessantes e desde 1990 até os dias hoje eles existem e fazem parte da memória ituiutabana daqueles que sempre compraram nesses ambientes. $\mathrm{O}$ teatro e o cinema funcionavam como atividades culturais atrativas para a população de Ituiutaba. $\mathrm{Na}$ época tinha o cine Bristol e o teatro Vianinha que trazia atrações interessantes. ( $9^{\circ} \mathrm{C}$ Grupo III, 2015).

A partir dos relatos destacados, reforçamos a importância de mobilizar os estudantes no processo de ensino e aprendizagem. O trabalho com jornais nas aulas de história permite reconectar saberes fazendo ligação com a vida prática.

A etapa seguinte foi elaborar com os alunos uma apresentação Power Point para mostrar aos colegas os resultados das pesquisas. Os encontros para a construção da apresentação em slides foram feitos também na biblioteca municipal da cidade. Os alunos empenharam-se para a realização da tarefa, comparecendo a todos os encontros em horário extra classe. Esse trabalho foi orientado e supervisionado por monitores contribuintes do projeto.

A última e não menos importante etapa foi a exposição dos trabalhos, feita pelos três $9^{\text {os }}$ anos no auditório da escola. Os alunos ficaram preocupados, ansiosos e nervosos para a exposição do trabalho, pois nunca tinham passado por uma experiência como aquela. Essa 
etapa foi uma das tarefas mais prazerosas. Foram convidados a participarem como ouvintes a diretora da escola, o professor coordenador do projeto e os monitores colaboradores dessa fase do projeto.

Os alunos sentiram-se à vontade para usar a imaginação e a criatividade para produzir os slides e navegar sobre as diferentes ferramentas disponíveis no Power Point. Para eles foi um momento de aprendizado e descontração ao mesmo tempo, pois de acordo com a fala de um dos participantes "nem parece que estamos fazendo um trabalho de História, eu nem gosto dessa matéria, mas isso tá muito bom". Como já dito, um dos objetivos era driblar a rotina da sala de aula e produzir conhecimento histórico de forma mais interativa com os alunos.

\section{Considerações finais}

Concordamos com Silva Júnior e Sousa (2014), ao afirmarem que ao recorrer às várias fontes e linguagens, o desafio do professor é mobilizar o aluno para a exploração e análise de documentos, fontes e linguagens, apreendendo outras histórias, não como simples complemento de informação, ou confirmação de uma "história única". Nessa atividade, evidenciamos o envolvimento dos estudantes na busca de compreender aspectos da história local. Estabeleceram diálogos com parentes mais velhos buscando relacionar com o conteúdo estudado.

A atividade revelou que a história é produto de uma verdadeira construção. Um conteúdo de saber transmitido e aprendido que possui formas singulares. São desafios da didática da história, conhecer e problematizar como o aprendizado histórico se efetiva nas salas de aula, como as crianças e jovens aprendem história. Os resultados do desenvolvimento da sequência didática com os estudantes nos levam a repensar a relação professor/aluno, o tipo de aprendizado histórico produzido a partir dessa relação e, como é possível associar o conhecimento produzido por eles com a vida prática cotidiana. A partir disso formularmos proposições à didática da história.

O trabalho feito com os alunos a partir do uso do jornal como fonte histórica permitiu a eles proximidade com a fonte, objeto de trabalho do historiador, e autonomia para pesquisa. Eles não se prenderam apenas ao que já estava pré-estabelecido, se permitiram analisar outras questões mesmo que a título de curiosidade de acordo com o que encontravam nos jornais.

O tema da sequência referente à história local foi o que nos levou a usar os jornais, já que lá poderíamos encontrar o maior número de informações possíveis sobre a cidade e permitir, aos jovens estudantes envolvidos na pesquisa, compreender que eles são sujeitos 
históricos do espaço em que vivem e que o conhecimento histórico pode ser elaborado por todos.

Compreendemos que para ensinar história é necessário, além do conhecimento histórico, saber orientar os alunos no tempo e contribuir de forma sistematizada para a formação do pensamento histórico, enquanto sujeito constitutivo da própria história, a partir das demandas apresentadas pela sociedade na qual estamos inseridos. As colocações que os alunos fizeram durante a realização do trabalho são válidas e devemos valorizá-las, visto que contribuem para o aprendizado. Associar os elementos cotidianos com a história é importante para a construção de um futuro melhor e isso é conhecimento histórico contribuindo para uma vida mais engajada nas questões socioeconômicas e culturais desses jovens enquanto cidadãos. Dessa forma, a realização da sequência didática na escola nos fez refletir que é possível um ensino de história de qualidade e utilidade para a vida dos alunos das escolas básicas.

A didática da história, como campo de saber deve insistir em estreitar o diálogo entre o trabalho dos historiadores e a educação escolar e não se limitar à transposição do conhecimento histórico acadêmico para os estudantes da educação básica. Defendemos a proposição de que a didática da história analise todas as formas e funções do raciocínio e do conhecimento histórico na vida cotidiana e prática. Isso inclui o papel da história na opinião pública, os usos da história nos meios de comunicação de massa, bem como considera as possibilidades e os limites das representações históricas nas diferentes fontes e linguagens.

Acreditamos que os conteúdos históricos nas salas de aula devem ser resultados de problemas, debates, pesquisas e polêmicas. Nessa perspectiva, a finalidade da educação escolar, em específico do ensino de história é formar cidadãos críticos e responsáveis, capazes de compreender a complexidade e tomar parte do debate democrático. Assim, as aulas de história não podem se caracterizar meramente por exposições dialogadas, mas por um espaço de interação entre estudantes, professores, documentos, fontes variadas e diferentes linguagens.

\section{Referências bibliográficas}

ANDRÉ, Marli Eliza D. A. de. Etnografia da prática escolar. Campinas, SP: Papirus, 1995. BITTENCOURT, Circe Maria Fernandes. Ensino de História: fundamentos e métodos. São Paulo: Cortez, 2004. 
CARDOSO, Oldimar. Para uma definição de Didática da História. Revista Brasileira de História. São Paulo, v. 28, n. 55, p. 153-170, 2008.

KARNAL, Leandro. História na sala de aula: conceitos, práticas e propostas. São Paulo: Contexto, 2008.

NAPOLITANO, Marcos. Como usar o cinema na sala de aula. São Paulo: Contexto, 2009.

SAMUEL, Raphael. História Local e História Oral. Revista Brasileira de História. v. 9, n. 19, set. 1989/fev. 1990. p. 219-242.

SANTOS, Milton. Espaço e método. São Paulo: Nobel, 1985.

SILVA JÚNIOR, Astrogildo Fernandes; SOUSA, José Josberto Montenegro. A pesquisa no ensino de história: $O$ potencial das diferentes fontes e linguagens. In: CONGRESSO INTERNACIONAL DE HISTÓRIA, 2014, Jataí, GO. Anais.... Jataí, GO: CIH, 2014. p. 1 19. Disponível em: http://www.congressohistoriajatai.org/anais2014/Link\%20(22).pdf. Acesso em: 10 dez. 2015.

VIANNA, Heraldo Marelim. Pesquisa em educação: a observação. Brasília: Líber Livro Editora, 2007.

Artigo recebido em: 03.04.2020 Artigo aprovado em: 05.07.2020 
